Cover Page

\title{
THE OCCUPATION OF LOOKING FOR WORK: AN INTERPRETATIVE PHENOMENOLOGICAL ANALYSIS OF AN INDIVIDUAL JOB-SEEKING EXPERIENCE
}

\section{AUTHORS}

1) Marna de Bruyn, (The Living Link, RSA), $117^{\text {th }}$ Street, Parkhurst, Johannesburg, 2193, Tel: +27 11788 8249, marna@thelivinglink.co.za

2) Dr Josh Cameron (University of Brighton, UK), School of Health Sciences, University of Brighton, Robert Dodd Building, 49 Darley Rd, Eastbourne, BN20 7UR. Tel: +44 (0)1273 643774. Email: j.cameron@brighton.ac.uk. Orchid ID: orcid.org/0000-0002-7467-7984 Affiliation where research was conducted: University of Brighton, UK.

Corresponding author: Josh Cameron.

\section{ACKNOWLEDGEMENTS}

First and foremost the authors would like to thank the research participant for sharing her at times challenging experiences. This work was supported by a thesis grant provided to the first author as part of a fully-funded Chevening UK Government Scholarship. It has also been supported by the Economic and Social Research Council (ESRC) Imagine Programme under grant ES/K002686/2. The contents are solely the responsibility of the authors and do not necessarily represent the official view of the ESRC. Information on ESRC is available on http://www.esrc.ac.uk/. Finally the authors are grateful to the anonymous journal article reviewers and editor for their constructive comments which we consider has helped us to improve this article from its original version.

\section{DISCLOSURE STATEMENT}

The authors declare no conflict of interest, financial or otherwise, arising from the research presented in this article.

\section{ETHICS APPROVAL}

This study was approved by the University of Brighton, School of Health Sciences, School Research Ethics and Governance Panel dated 01.04.2015. 


\title{
THE OCCUPATION OF LOOKING FOR WORK: AN INTERPRETATIVE PHENOMENOLOGICAL ANALYSIS OF AN INDIVIDUAL JOB-SEEKING EXPERIENCE
}

\begin{abstract}
This qualitative study explored the meaning of job-seeking, as a human experience and occupation, as it is understood by an individual job-seeker within the United Kingdom. Interpretative phenomenological analysis was used to understand the meaning of job-seeking as a lived experience. A series of three, in-depth interviews were conducted with a single participant at various stages of the job-seeking experience. After individual and cross analyses of interview transcripts, three master themes were developed that demonstrated how the job-seeking experience was understood. These were: (1) understanding the self and identity, (2) understanding relationships, (3) understanding job-seeking as a journey. These results are discussed in the context of previous studies of job-seeking and occupational perspectives that focus on meaning in human occupation. The study concludes that jobseeking is a rich human occupation in which its form, function and meaning are influenced by internal and external sources of resilience related to the person, their occupations and environment. Future research could build on these insights by considering the efficacy of these internal and external supports and how job-seeking varies across different cultural and social contexts.
\end{abstract}

Key Words: Job-seeking, interpretative phenomenological analysis, lived experience, resilience, self-identity.

\section{INTRODUCTION}

The Office for National Statistics (2015) reported more than 800000 claimants of a Jobseeker's Allowance in the United Kingdom (UK) during December 2014. Despite the decrease in claimant numbers since November 2011, the number of UK jobseekers may be higher as some individuals do not or are unable to access this allowance. As potentially more adults engage in job-seeking, it may become an occupation of increasing interest to occupational science researchers. Arguably, occupational deprivation or disruption can occur when a person does not engage in paid employment despite an expressed desire or need (Whiteford, 2000). Individuals searching for employment may do so to overcome the 
occupational deprivation associated with involuntary unemployment. Job-seeking has previously been classified in occupational categories of work or productivity (The American Occupational Therapy Association, 2014; Kielhofner, 2008). For the purposes of this study, job-seeking is regarded as the process where an unemployed adult actively seeks paid employment. This study explored the meaning of job-seeking as an experience and occupation as understood by an individual job-seeker within the UK.

Job-seeking could be defined in a number of different ways and may include a range of job-search activities, both formal and informal (Lindsay, 2010). Job-seekers may include those individuals who are actively seeking employment as well as those wanting employment without actively job-seeking (Vesalainen \& Vuori, 1999). Arguably, the concept of passive job-seeking seems a misnomer as ‘seeking' implies some level of search activity. Such contradictions reflect the scope and complexity of how, when, why and where people search for jobs.

A number of factors may influence an individual's job-seeking experience (Brown \& Konrad, 2001). These factors may be intrinsic to an individual job-seeker or located in their social, political, physical or temporal environment. The following intrinsic factors have been suggested as examples that may affect job-seeking behaviour: emotional experience (Bonaccio, Gauvin \& Reeve, 2014; Bulstein, Kozan \& Connors-Kellgren, 2013); victimperpetrator sensitivity (Stavrova, Schlösser \& Baumert, 2014) and action-state orientation (Wanberg, Zhu \& van Hooft, 2010). Extrinsic factors include: financial hardship (Wanberg, Rotundo \& Kanfer, 1999), socio-economic support (Bulstein et al., 2013, Manning, 2009) and social capital (Bloch, 2013; Lindsay, 2010). Wanberg, Zhu and van Hooft (2010) portrayed job-seeking as a 'rollercoaster' (p.801), highlighting the complexity and interaction of multiple factors that may affect job-seeking behaviour.

Job-seeking, as all other human occupations, may be seen as a subjective experience, rich with meaning (Reed, Hocking \& Smythe, 2011). Hammell (2014) has suggested that occupational perspectives should focus on meanings as opposed to categorisations of human occupation. With regard to job-seeking, this may be best achieved by better understanding the meaning of job-seeking for current job-seekers. Notably limited in literature were studies focusing on understanding job-seeking as a lived experience. Arguably, research that focuses on an in-depth understanding of the meaning job-seeking as a human experience may add to the breadth and depth of current knowledge. The authors were both drawn to this topic due to practice and research interests and experience in vocational rehabilitation. 


\section{METHODOLOGY}

\section{Research Aim}

The aim of this study was to explore the understanding of the job-seeking experiences of a person living in the United Kingdom.

\section{Interpretative Phenomenological Analysis}

To achieve this aim, an in-depth understanding of how an individual interprets their job-seeking experience was sought. Interpretative phenomenological analysis (IPA) was selected as research methodology. Smith, Flowers and Larkin (2009) proposed IPA as an appropriate methodology for understanding how people make sense of significant life experiences. This interpretative emphasis of IPA is largely influenced by Heideggerian phenomenology and Gadamerian hermeneutics (Smith et al., 2009). The associated interpretive lens of the researchers drew on concepts and theory from occupational science (Hammell, 2014; Laliberte-Rudman 2002).

Within the chosen methodology, interpretation of the job-seeking experience emerged through collaboration between the researcher and participant (Larkin, Watts \& Clifton, 2006). Generalization of findings to a larger group was not the aim of this study, rather the intent was to portray an individual's job-seeking experience with authenticity. Pringle, Drummond, McLafferty and Hendry (2011) noted that IPA is not an endeavour to seek a single truth and it was assumed that multiple possible 'truths' of the job-seeking experience may emerge. IPA was highly suitable for a single case study due to its idiographic focus (Smith et al., 2009). Several studies have demonstrated successful use of IPA with single case analyses of various phenomena (see Brunsden \& Hill, 2009; Eatough \& Bramley, 2005; Glasscoe \& Smith, 2011).

\section{METHODS}

\section{Recruitment}

Recruitment involved a third party recruitment strategy. Recruitment leaflets (with the first author's contact details) were provided to affiliates within the first author's social network (providing access to church, hobby/activity and charity contacts) who were asked to pass them on to people who they thought might be interested in participating. Key inclusion/exclusion criteria were that the participant should have been job seeking in the UK for at least 3 months and that they should not already have a job and that they should not be 
receiving specialist health treatment other than routine primary care. A total of three potential participants responded. The final participant selected for this study was recruited via a charity supporting job-seekers. This person was selected on the pragmatic grounds that they could most easily attend the three planned interviews.

\section{Participant}

At the start of the study, Hazel (pseudonym), a 55-year old female, was job-seeking for a period of three months. She had started job-seeking following redundancy from her former job as a community development worker at the local council, where she had worked for 37 years. Initially, she was searching for administrative employment. By the end of data collection, Hazel had abandoned job-seeking to pursue a yearlong, full-time course in counselling with the future aim of completing a university degree. Hazel was the youngest of six children and lived in the town where she grew up. She had been with her husband since she was 18 years old and they had two children. Her 24-year old son lived at home, both her husband and son were employed.

\section{Data Collection}

A series of three semi-structured interviews, each lasting between 45 and 90 minutes, were conducted over a 3-month period. Interviews were conducted by the first author and took place in a private room within a public building and audio-recorded for transcription. A preliminary interview schedule was developed before each interview using graded, openended questioning and an empathetic interviewing style (Vandermause \& Fleming, 2010).

The use of successive interviews allowed for increasing rapport to develop between the researcher and participant (Snelgrove, 2014) and helped obtain authentic and rich data that helped to capture the participant's experiences at different points in time of the jobseeking journey. Rigour in the analytic process was enhanced by multiple interviews allowing for further exploration of certain aspects and verification of primary themes emerging from initial transcript analyses (Buchbinder, 2010).

\section{Data Analysis}

Audio recorded interviews were transcribed verbatim. Personal and demographic details that could result in the identification of the participant were altered. Data analysis followed the steps outlined by Smith et al. (2009) while acknowledging that the IPA research process is not intended to be rigid or prescriptive (Larkin et al., 2006). Data analysis was conducted in five stages, allowing for a systematic and detailed analysis of the parts and the 
whole of the entire case. Each interview was firstly treated as a single case. This allowed indepth analysis of each interview before performing analyses across all three interviews. A diagrammatic representation of the data analysis process is displayed in Figure 1.

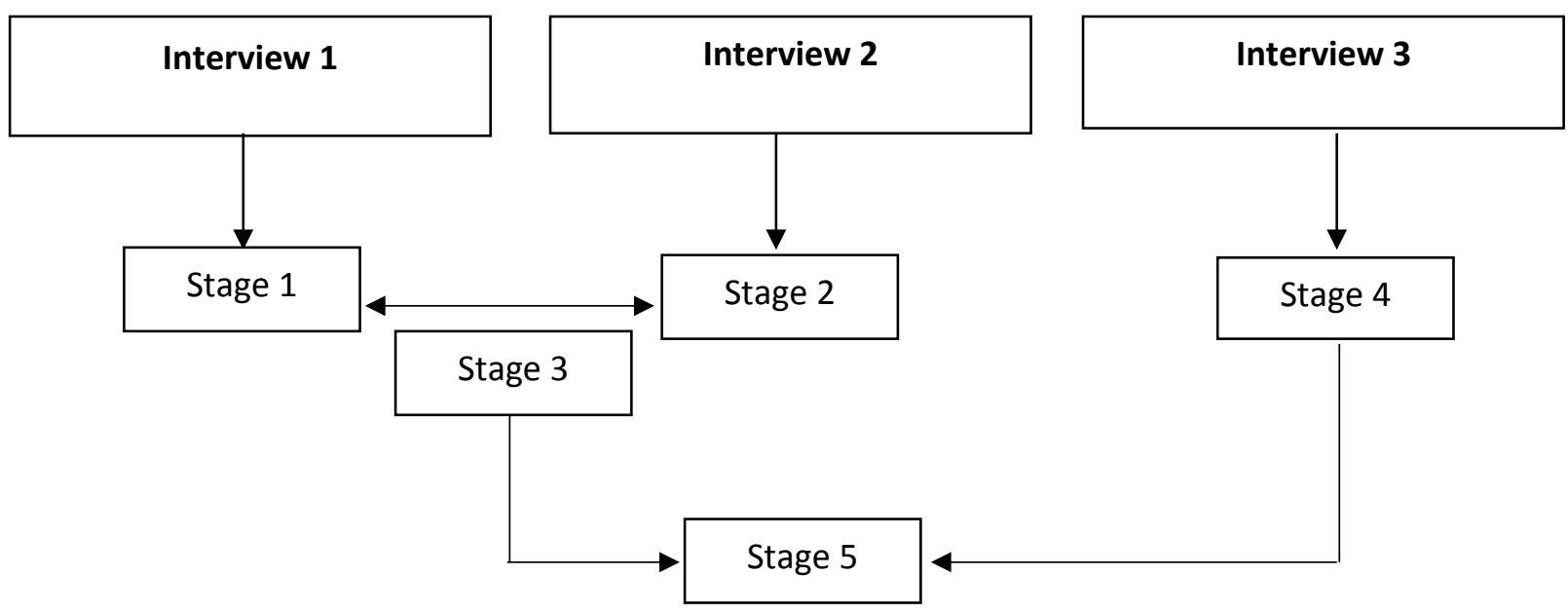

Fig. 1: Diagrammatic representation of the stages of data analysis.

Analysis focused on the researchers' interpretations of Hazel's understanding of the job-seeking experience. Since interpretive phenomenology acknowledges that interpretation of experience is necessarily influenced by the researcher's background and pre-understanding of phenomena (Finlay, 2011), the first author maintained a reflexive research journal and used discussions with the second author (their academic research supervisor) to support a critical awareness of of the interpretation process. The first author primarily conducted the analysis discussing examples from each stage with the second author. To increase the rigour of analysis data analysis was conducted in five stages, allowing for a systematic and detailed analysis of the parts and the whole of the entire case. Each interview was firstly treated as a single case. This allowed for an in-depth analysis of each interview before performing analyses across all three interviews. In Stage 1,2 and 4, a line-by-line analysis of each interview transcript was carried out to develop a set of emergent themes (Smith et al., 2009). These initial themes were identified by considering the comments made on the content of speech, use of language and the context of the dialogue. Secondly, cross analyses between interviews were carried out by comparing the clusters of emergent themes from each interview (Stage 3, 5). This involved re-organisation and a reduction of themes to produce a set of master themes. While these stages were carried out as distinct stages, the interpretation 
of each preceding stage influenced the analysis of the following stage. An auditable trail of each stage of data analysis was maintained by photographic and electronic records.

Meyrick (2006) suggested that rigour in qualitative research demands that studies are both transparent and systematic. In addition to the rigour outlined above in the data analysis steps, transparency was sought through a record of the data analysis process. While IPA remains an inherently interpretative approach, the credibility of the interpretative process was increased by participant verification, repeated interviewing as well as supervisory discussions of findings (Lincoln and Guba, 1985; Baillie, 2015).

\section{ETHICS}

This study was approved by the University of Brighton, School of Health Sciences, School Research Ethics and Governance Panel. Given the potentially sensitive nature of the phenomenon investigated, informed consent and anonymity were of particular importance. Detailed written and verbal information of the study, including the risk of distress, was provided to the participant before consent was obtained.

\section{FINDINGS}

From repeated individual and cross-analyses of the interview transcripts, three master themes were developed. These themes demonstrate how Hazel made sense of her job-seeking experience. These findings reflect Hazel's sense-making of job-seeking at three different time points and include the evolution of her sense-making as time progressed. (1) The first theme, Understanding self and identity, sets out how Hazel's understanding of herself and identity influenced how she made sense of job-seeking. This process included encountering threats to her identity. (2) The second theme, Understanding relationships, has a more outward focus demonstrating Hazel's interpretation of job-seeking in relation to the binaries of connections and disconnections and to visibility and invisibility. (3) The final theme, Job-seeking as a journey, considers the evolution of meaning across time by setting out her understanding of job-seeking as a dynamic process in which she experienced supports and set-backs some of which were in her control and some were not as she navigated her way through the search for employment. Each master-theme contained sub-themes that were polarized to demonstrate Hazel's understanding of job-seeking. The three master themes and related sub-themes are presented in Table 1 (see below). 
Table 1

Master themes and related sub-themes

\begin{tabular}{|l|l|}
\hline Master Theme & Sub-Theme \\
\hline \multirow{2}{*}{ Understanding self and identity } & The threat to and potential loss of identity \\
\cline { 2 - 2 } & Maintaining and regaining identity \\
\hline \multirow{2}{*}{ Understanding relationships } & Disconnection and Connection \\
\cline { 2 - 2 } & Invisibility and Visibility \\
\hline \multirow{2}{*}{ Job-seeking as a journey } & Job-seeking as a rollercoaster \\
\cline { 2 - 2 } & Adjustment and finding new direction \\
\hline
\end{tabular}

\section{Theme 1: Understanding self and identity}

Over the course of her job-seeking experience, Hazel's understanding of herself and her identity informed how she made sense of job-seeking. Hazel seemed to experience a threat to her identity, a partial loss of identity and struggled to maintain her sense of self.

\section{The threat to and potential loss of identity}

At the time of the first interview, Hazel had been job-seeking for approximately three months. Job-searching became an increasing threat to her identity as she continued to engage in job-seeking without success. She explained the futility of job-searching by personal fault.

Just even looking on the computer at jobs and thinking [..] 'that's too far away, that's not right, I haven't got the skills to do that'. It just makes me feel as if I'm not good enough. That after sort of [sighs] 37 years of working that I haven't worked hard enough because I can't fit into anything. [Interview 1]

The threat to identity increased as Hazel continued her job search. She appeared to be experiencing increasing inner conflict and questioned her experiences, abilities and career choices as job-seeking represented a process of personal failure.

I suppose I never thought I would be in this position. I never thought that I would be going to the Job Centre at 55 and not have the ability just to get a job.

[Interview 2]

After working for the council for 37 years, losing her job appeared to have a profound effect on Hazel's sense-making of job-seeking as a loss of identity. Additionally, by applying for a job in an administrative position Hazel regarded job-seeking as an experience of compromise where she would be expected to become someone else. She saw her decision to pursue alternative employment as one that would require a degree of personal sacrifice.

Because I was going down rather than up, I think in some ways that was a deliberate choice [sighs, pauses] but that would necessitate me maybe losing a bit of myself.

[Interview 3] 
A perceived loss of individuality informed her sense-making of job-seeking as a 'depersonalising' experience. Job-searching became a process that did not acknowledge individuality and was seen as a mechanical procedure. Online job-applications, telephone interviews and obligatory visits to the Job Centre were viewed as impersonal processes where unique individual attributes were not recognised or valued.

I suppose it feels almost robotic doing it on the computer. [..], that it's just a press of a button.. [Interview 3]

Overall, job-seeking became an experience that resulted in partial erosion of her sense of self.

\section{Maintaining and regaining identity}

Job-seeking became a process where Hazel had to maintain her identity by affirming her abilities. While the outcome of unsuccessful job applications resulted in disappointment and feelings of failure, the process of completing job applications were seen as reminders of her abilities. Also, engaging in alternative activities such as volunteering seemed to provide a sense of purpose that had been lost when she became unemployed. These feelings of competence and ability appeared to partially negate the threat job-seeking posed to her sense of identity.

When you send the application off it feels a little bit fulfilling. [..] because, I suppose, you'd done something positive, but also it reminds you what you can do.

[Interview 1]

The everyday experience of job-searching may have caused her to 'forget' her abilities and she required an external reminder to recall her capabilities. Additionally, Hazel used past work experience as a buffer against the threat posed to her identity. The struggle to maintain dignity caused frequents shifts in her sense-making of job-seeking as she moved back and forth between feelings of guilt and failure while simultaneously attempting to protect her sense of identity.

[After an unsuccessful job application] I suppose I hope, that it’s because I was too experienced for it. [Interview 2]

Abandoning job-seeking to pursue full-time education appeared to be a process where Hazel reclaimed her sense of identity. She seemed to experience the prospect of full-time study as an opportunity to regain an authentic identity. Job-seeking had led to a new sense of identity, that of a full-time student.

So yeah, just feels like: it’s about being me. 
[Interview 3]

\section{Theme 2: Understanding relationships}

Hazel appeared to interpret her job-seeking experience in relation to others, where it acted both as an inhibitor and enabler of relationships. At times, it caused feelings of isolation, disconnection and invisibility. Simultaneously, it created new opportunities for connection with others. Four oppositional sub-themes emerged: disconnection and connection; invisibility and visibility.

\section{Disconnection and Connection}

Job-seeking resulted in feelings of social isolation in various ways. Firstly, Hazel experienced physical loneliness as she no longer engaged in the daily interaction she had enjoyed at work. She was, quite literally, disconnected from other people.

It makes you feel depressed because you're alone and you haven’t got that, you know, day-to-day talking to people, which is what I was very much used to.

[Interview 2]

In addition to the physical isolation she experienced, job-seeking became an experience that she felt unable to share with others. The isolation seemed intensified by Hazel's age as she had friends who were retired but was unable to relate to their experience of voluntarily ending work. Hazel interpreted her job-seeking experience in comparison to others who she felt may be worse off. She viewed her experience as highly unique. Jobseeking became a process of alienation from others, beyond only physical separation.

I think not only the thing of being lonely because you're at home and you force yourself to go out. It's lonely because I don't know anybody else in the same position.[..] I’ve got a couple friends who are retired but it's not the same as not having a job but wanting to work.

[Interview 1]

Job-seeking also appeared to be a process of deliberate disconnection as Hazel purposefully distanced herself from other people in order to avoid sympathy. Her subjective experience of failure, as part of job-seeking, informed her decision to intentionally avoid certain social contact.

I don’t like that pity [...] So I sort of distance myself from other people.

[Interview 3]

Once Hazel terminated job-seeking, retrospectively, she viewed it as an experience that presented the potential for connection with others. It had changed her understanding of job-seekers, particularly those claiming welfare benefits. This allowed potential future social connections with people she had previously felt unable to relate to. Hazel’s first-hand 
experience of job-seeking represented a possible strength in her envisioned future career as a counsellor. It presented the potential for empathetic understanding other job-seekers' experience.

Maybe a better understanding of people that are going through that. [..] The fact that I have been through it and can empathize with people's experience.

[Interview 3]

Hazel repeatedly emphasised the value of external support from various sources within her social network. Support was seen as a lack of external judgment and pressure and included social acceptance and encouragement.

\section{Invisibility and Visibility}

Attending the Job Centre every fortnight represented a major part of Hazel's sensemaking of job-seeking. Initially, Hazel seemed to experience a degree of invisibility during these obligatory visits. Interactions with Job Centre staff were seen as a mere fulfilments of external criteria. The lack of visibility and authentic relationship in this context seemed to relate to Hazel's understanding of job-seeking as a depersonalising experience. The procedure was explained in a manner similar to a machinelike process.

\footnotetext{
When you go to the Job Centre you show them your book when you go in, they tell you where to go, you go up there, you sit down, nobody interacts with you, your name is called, you go and sit down, you show them your book and your ID or whatever. They don't really look at anything [... they don't ask what you've been doing, they don’t offer any help.

[Interview 1]
}

An additional element to the invisibility of job-seeking related to Hazel feeling overlooked for positions that she was convinced she could do. She seemed to engage in continuous self-dialogue of how to increase her visibility to potential employers by making her CV 'stand out'. Hazel seemed to interpret external recognition as confirmation of her visibility to others. Getting an interview was viewed as confirmation that she was, in fact, visible to other people as her skills were 'seen' by a potential employer.

It cheered me up. Because I thought: 'Oh! I, obviously, got some skills that somebody could see was relevant for what they were looking for'.

[Interview 3]

\section{Theme 3: Job-seeking as a journey}

Job-seeking reflected a temporal journey between past, present and future. 


\title{
Job-seeking as a rollercoaster
}

Hazel viewed job-seeking as a rollercoaster where she repetitively transitioned between feelings of optimism, disillusionment and despair.

I think it's a bit of a cliché.- a rollercoaster. You know, you might just fire off a CV and think: 'Ah, well I may hear something in a couple of days’. And then.. no..

[Interview 2]

Retrospectively, Hazel regarded this process as a repetitive cycle. This may have contributed to her understanding of her job-search efforts as pointless and seemed to cause increasing feelings of frustration. She appeared to feel trapped in this cycle and sought a way out.

\begin{abstract}
I think I was starting to feel I wouldn't get out of that cycle. That it's gone on too long. [...] That I was just stuck on that and there was just no prospect of anything really.

[Interview 3]

Initially, job-seeking was seen as 'cathartic'. As time progressed her understanding of the experience changed dramatically. She experienced increasing fear and anxiety that she would be unable to find a job. Her understanding of job-seeking as an escape from previous stressors changed to job-seeking as an experience she wanted to escape from.
\end{abstract}

\begin{abstract}
A period of about six weeks could just be cathartic in the sense of not working and just relaxing for a few weeks. But then, after that period it felt like [long pause] the pressure was on me to get something. [...] After three months it begins to feel like you're a total failure because your chances of getting a job are lessening all the time. [..] So I was frantically looking through the job opportunities that came up thinking 'Could I do that one? Could I do that one? Could I do that one?' and being more frightened that [..] there wasn't going to be anything.

[Interview 3]
\end{abstract}

Job-seeking had become a process of sudden social demotion, completing what she saw as decade of steady decline. This process of regression in social status resulted in feelings of inferiority.

And in the last 10 years, I like keep on going down a notch. And now, you know, I've been right down at the bottom.

[Interview 1]

Similar to a ride on a rollercoaster, Hazel seemed to understand job-seeking as a process where control was lost. Hazel did not voluntary enter job-seeking and was obliged to attend the Job Centre every fortnight to fulfil compulsory search requirements.

If you've got limited choices, [..] your control is taken away from you. [Interview 2]

The experience became increasingly uncertain and unpredictable. As time progressed Hazel engaged in a self-dialogue about whether she wanted to remain on this journey. Finally, she understood her decision to end job-seeking as a relief. 


\section{Adjustment and finding new direction}

Job-seeking became an experience that required Hazel to occupy the void caused by the loss of her job.

Because I'm keeping myself busy with doing the [maths course] and the volunteering, I don't feel so bad because I'm not sitting around not doing anything.

[Interview 1]

The actual search for employment did not seem to be sufficient to fill the emptiness caused by the loss of her job. As part of job-seeking, Hazel engaged in a process of restructuring daily life and this, in turn, caused her to question her search for administrative employment.

I think what I was doing made me question again as to whether going down the administrative route was the right route and then if that wasn't the right route, what was the right route? Because I wasn't getting any interest from anybody about doing admin work so [..] I wasn’t sure where to go. [Interview 3]

Similar to a lost traveller recalculating a chosen route, job-seeking became a process that necessitated re-evaluation. Hazel seemed to experience the need to reclaim control of this journey. The search for employment was more than a search for a job, it became a search for broader life experience.

Some of it is about wanting to be independent and [..] part of other experiences. So not just, I don't mean just, but not somebody's wife, mother, housekeeper.

[Interview 3]

Job-seeking presented an opportunity to pursue a different future direction as she decided to apply for a full-time pre-graduate course. Job-seeking had enabled the emergence of new future possibilities as the search for employment became a search for education.

So that's why I hadn’t done it previously. [..] because I wouldn't 've seen any way that it would have been very much benefit to me. [..] yeah, it feels like a new start... [Interview 3]

\section{DISCUSSION}

This study aimed to explore how a person living in the UK understands their jobseeking experiences. Hazel's rich individual experiences appear consistent with Russel’s (2011) conclusion that job-seeking represents a unique narrative (Russel, 2011). For her jobseeking represented a significant life experience and occupation that was interpreted through a dynamic sense-making process. Doing, being, becoming and belonging have been proposed as dimensions of meaning in human occupation (Wilcock, 2006; Hammell, 2014). Hazel's interpretation of her job-seeking experience reflected these occupational science dimensions 
of meaning. Job-seeking was not merely the act of searching for employment, but an experience that shaped Hazel's sense of being, becoming and belonging.

\section{Understanding self and identity}

From an occupational perspective, human occupation may be viewed as a source of identity (Unruh, 2004; Abrahams, 2008) and self-expression (Laliberte-Rudman, 2002). Not surprisingly, being employed as community development worker for 37 years represented a major part of Hazel's identity. Her experience of profound identity loss following redundancy, reflects the findings of a cross sectional survey of 173 adults, where unemployment and job searching appeared particularly distressing for people who viewed work as a core component of their identities (Creed, Lehman \& Hood; 2009).

Additional to the loss of her identity as worker, job-seeking also became a threat to Hazel's personal identity as she feared that she would need to compromise who she was in order to get a job. Job-seeking participants in a qualitative study of unemployment and employment transition in the United Kingdom experienced similar identity crises (Giuntoli, Hughes, Karban \& South; 2015). For these individuals, job-seeking not only represented the loss of identity as worker, it also required the assumption of a 'new social status and role' (Giuntoli et al., 2015, p.400). In Hazel's case the status of 'a job-seeker on benefits' represented a new and degraded social identity, one where she became a part in an impersonal, machine-like process. While financial hardship may present a common job search motive (Wanberg, Rotundo \& Kanfer, 1999; Giuntoli et al., 2015), it has been suggested that some mature job-seekers may primarily seek employment for intrinsic reasons (Nakai, Chang, Snell \& Fluckinger, 2011). In Hazel’s case, her loss of income was seen as regrettable, but job-seeking primarily appeared to be a search for purpose and identity rather than a search for a source of income.

Despite the apparent negative connation Hazel attached to her identity as a job-seeker, job-seeking represented a route to recover her lost identity as a worker. However, her struggle to find appropriate vacancies and failure at job applications progressively changed her understanding of job-seeking to an experience, ultimately, amounting to personal failure and further identity loss. In a narrative inquiry amongst job-seekers at a career centre in the United States, Bulstein et al (2013) found some participants viewed job search failure from an 'individual-level perspective' (p.260) where personal deficits were identified as the cause for continuing unemployment. Alternatively, participants who viewed unemployment from a macro-level perspective tended to attribute their unemployment to external factors such as 
economic or employment policies. Hazel appeared to understand her inability to find suitable employment from both an individual and macro-level perspective. She questioned her career choices and work experience but also resented the fact that job-searching was an exercise of 'ticking boxes' to fulfil external requirements and criteria.

Despite her dual perspective of her job search failure, Hazel's understanding of herself and her identity informed her sense-making of job-seeking. Being and becoming, as suggested dimensions of meaning in occupation (Wilcock, 2006), were reflected in Hazel's ongoing sense-making of who she was and who she would potentially become, as she continued to navigate her way through the search for employment. Development of positive self-identity is said to be a key internal resource in promoting the resilience of people facing adversities (Ungar et al 2007). Once Hazel had abandoned job-seeking to pursue full-time education, in addition to the novel identity of student, she seemed to have regained a positive self-identity.

\section{Belonging and not belonging through relationships and occupations}

While occupation represents a source of personal identity, human occupation also provides a sense of belonging (Hammell, 2014). Belonging in turn is identified by Hart, Blincow and Thomas (2007) as a central category of resilience that may either be undermined by adversities or bolstered by resilient 'moves'. Hazel valued the sense of belonging she had experienced at work. In contrast to working in a team, job-seeking remained a solitary activity, mostly carried out in isolation from others, supporting the suggestion that jobseeking becomes an increasingly lonely experience for people who remain unemployed (Lindsay, 2010). Social identity may be shaped by occupational engagement (LaliberteRudman, 2002) as occupations presents the potential for connection with others (Hammell, 2014). Hazel perceived working as a means for social connection, but viewed job-seeking as an experience that disconnected her from friends and family who were retired or voluntarily unemployed. Several studies have confirmed the value of social support during job-seeking (Eg., Bulstein et al., 2013; Johnson \& Jackson, 2012) and Hazel valued external support received from various sources within her social network during her job-seeking experience.

In contrast to the support received from these sources, obligatory visits to the local Job Centre contributed significantly to Hazel's experience of job-seeking as one of invisibility and disconnection. Hazel's experience appeared strikingly similar to experiences reported by participants in an Australian study of mature job-seekers' at governmental jobseeking support agencies, who reported feeling demoralised, devalued and ignored (Kossen 
\& Hammer, 2010). The notion of invisibility has been reported amongst diverse sample populations (for e.g. Blessett \& Pryor, 2013; Harrison, 2001; Whitzman, 2006). Overarching these diverse experiences is the understanding that one is unintentionally or purposefully not ‘seen’ or acknowledged by others. In Hazel’s case, invisibility appeared an ambiguous construct. For example, she sought increased visibility when applying for jobs but did not want to be seen, or potentially pitied, by former colleagues. Hazel's experience of being 'overlooked' for administrative positions resonates with the experiences of older women seeking clerical work through private employment agencies in New Zealand (Handy \& Davy, 2007). The tension between the need for visibility and invisibility in human occupations, such as job-seeking, may warrant further research.

Hammell (2014) proposed that people may connect through occupations. In relation to these roles of social connections and occupations, Cameron, Sadlo, Hart and Walker (2016) have argued that, in addition to the established concept of social capital (Lindsay, 2010) there is a need for a new concept of occupational capital, defined as: "a combination of accessible external opportunities and supports for occupational participation and internal capacities and skills to access this” (p.281). People in adverse situations, such as Hazel, may find their occupational capital reduced, yet may also seek to deploy occupational capital to overcome the challenges they face. Once Hazel had terminated job-seeking, it presented the potential for connection with other, current or former, job-seekers and with new occupations associated with her decision to undertake formal education.

\section{Job-seeking as a journey}

Human occupations may be understood in the context of time, as they shape present and future states of being (Pemberton \& Cox, 2015). For Hazel, job-seeking reflected a temporal journey between past, present and future.

Hazel appeared to understand job-seeking as a journey where she often had little or no control over her direction. Creed et al. (2012) suggested that job-seekers’ perceptions of control were important contributors to experiences of well-being. Hazel became a job-seeker following redundancy, a process she had little control over. Additionally, she had to comply with the requirements of a claimant of a Job-seeker's Allowance. Experiences of reduced control have been reported in various studies of job-seeking (Anaf, Newman, Baum, Ziersch \& Jolley, 2012; Giuntoli et al. 2015). The impact of welfare policies on job-seeking behaviour remains controversial as requirements for compliance from claimants may dictate how people, like Hazel, search for jobs (Wright, 2012). This points to the value of ecological 
understandings of resilience which do not responsibilise individuals for failing to display resilience to external challenges but rather consider whether it is systems, such as welfare policies, which need to be changed to support individual and social resilience (Hart et al, 2016).

Hazel experienced job-seeking as a repetitive cycle of optimism, disillusionment and despair. Similar to Hazel's job-seeking experience, participants in a qualitative study of jobseekers in the United Kingdom, reported frustration, lack of control and a 'sense of despair' while searching for jobs during the 2009-2010 economic recession (Giuntoli et al. 2015, p. 401). While the economic and political context of Hazel's job-seeking is not the same as for job-seekers in the 2009-2010 economic recession, her subjective experience appears very similar. As Hazel continued job-seeking she viewed the future as increasingly unpredictable and uncertain. Ultimately, despite this unpredictability, she saw her search for employment as a means to connect with broader life experience. Human occupation, such as job-seeking, may assume a deeper meaning according to the occupational value assigned to it (Persson, Erlandsson, Eklund \& Iwarsson, 2001). In Hazel’s case, job-seeking was a search for a former valued occupation, paid work. However, as she struggled to access employment, she decided to pursue full-time education as a means to a potential new career.

\section{Limitations and further research directions.}

While this study represents a rich account of an individual job-seeking experience in one social and cultural context, the idiographic focus may limit the transferability of findings (Lincoln \& Guba, 1985). However, it is hoped that the description provided is adequate in depth and richness, to allow readers discretion as to the transferability of findings. Furthermore, the required level of interpretation in IPA research remains debatable as IPA researchers balance the need for adequate depth in interpretation while avoiding importation of meaning from outside the original transcript (Smith et al., 2009). The results of this study, therefore, reflects one possible interpretation of an individual job-seeking experience. Further research could investigate multiple narratives across different cultural and social contexts to gain insight into experiences which are unique and those which are shared. A focus on internal and external barriers and enablers to the job seeking process is also suggested. More broadly, occupational scientists may consider exploring other life narratives to gain further insight into the process by which the form, function and meanings of occupation interact and become revised through performance influencing a person's identity and life trajectory. 


\section{SUMMARY}

Job-seeking represents a significant occupation and life experience for many adults worldwide. This study investigated how job-seeking was understood by an individual jobseeker in the United Kingdom. A series of 3 in-depth interviews revealed how Hazel, a 55 year-old female, experienced job-seeking following redundancy from long-term employment. Using Interpretative Phenomenological Analysis (IPA) three master themes were developed to demonstrate how job-seeking was understood. The first theme related to Hazel's understanding job-seeking in relation to herself and her sense of identity. The second theme demonstrated how Hazel understood job-seeking in relation to other people and occupations. The final theme reflected Hazel's understanding of job-seeking as a temporal journey. Overall, these master themes demonstrate the various levels of meaning in human occupation (Wilcock, 2006; Hammell, 2014).

While the findings of this case study do not reflect the experience of all job-seekers, they highlight the importance of a greater understanding of job-seeking as a human occupation. Thus in terms of the occupational science constructs of form, function and meaning (Larson and Zemke 2003), Hazel began a search whose function was to find new employment. The form it took involved encountering supports and barriers which often felt out of her control shaping how she performed the search. In the process of this search, the meaning she ascribed to it and her future aspirations shifted such that she revised the original functional aim to pursue full-time study. This single case study demonstrates that job-seeking is more than an act of searching for employment but is a rich human occupation influenced by internal and external sources of resilience related to the person, their occupations and environment.

Word Count: 7379

\section{REFERENCES}

Abrahams, T. (2008). Comment: Occupation, identity and choice: A dynamic interaction. Journal of Occupational Science, 15(3), 186-189. doi: 10.1080/14427591.2008.9686629

American Occupational Therapy Association. (2014). Occupational therapy practice framework: Domain and Process (3rd Edition). American Journal of Occupational Therapy, 68(Suppl.1), 1-48. doi: 10.5014/ajot.2014.682006 
Anaf, J., Newman, L., Baum, F., Ziersch, A., \& Jolley, G. (2012). Policy environments and job loss: Lived experience of retrenched Australian automotive workers. Critical Social Policy, 33(2), 325-347. doi: 10.1177/0261018312457858

Baillie, L. (2015). Promoting and evaluating scientific rigour in qualitative research. Nursing Standard, 29(46), 36-42. doi: 10.7748/ns.29.46.36.e8830

Blessett, B., Pryor, M. (2013). The invisible job-seeker: The absence of ex-offenders in discussions of diversity management. Public Administration Quarterly, 37(3), 433455. Retrieved September, 8, 2015 from http://web.a.ebscohost.com.ezproxy.brighton.ac.uk/ehost/pdfviewer/pdfviewer?sid=8 65b20dc-6e65-4142-80fe-ef28c69988e2\%40sessionmgr4003\&vid=1\&hid=4212

Bloch, A. (2013). The labour market experiences and strategies of young undocumented migrants. Work, Employment and Society, 27(2), 272-287. doi: $10.1177 / 0950017012460313$

Bonaccio, S., Gauvin, N., \& Reeve, C. (2014). The experience of emotions during the job search and choice process among novice job seekers. Journal of Career Development 41(3), 237-257. doi: 10.1177/0894845313486354

Brown, D.W., \& Konrad, A.M. (2001). Job-seeking in a turbulent economy: Social networks and the importance of cross-industry ties to an industry change. Human Relations, 54(8), 1015-1044. doi: 10.1177/0018726701548002

Brunsden, V., \& Hill, R. (2009). Firefighters’ experience of strike: An interpretative phenomenological case study. The Irish Journal of Psychology, 30(1), 99-115. doi: 10.1080/03033910.2009.10446301

Buchbinder, E. (2010). Beyond checking: Experiences of the validation interview. Qualitative Social Work, 10(1), 106-122. doi: 10.1177/1473325010370189

Bulstein, D.L, Kozan. S., \& Connors-Kellgren, A. (2013). Unemployment and underemployment: A narrative about loss. Journal of Vocational Behaviour, 82, 256265. doi: 10.1016/j.jvb.2013.02.005

Cameron, J., Sadlo, G., Hart, A., \& Walker, C. (2016). Return-to-work support for employees with mental health problems: Identifying and responding to key challenges of sick leave. British Journal of Occupational Therapy, 79(5) 275-283. doi: $10.1177 / 0308022615627176$

Creed, P.A., Hood, M., \& Leung, L.Y. (2012). The relationship between control, job seeking, and well-being in unemployed people. Journal of Applied Social Psychology, 42(3), 689-701. doi: 10.1111/j.1559-1816.2011.00798.x

Creed, P.A., Lehman, K., \& Hood, M. (2009). The relationship between core selfevaluations, employment commitment and well-being in the unemployed. Personality and Individual Differences, 47(4), 310-315. doi: 10.1016/j.paid.2009.03.021 
Eatough, V., \& Bramley, N. (2005). The experience of living with Parkinson's disease: An interpretative phenomenological analysis case study. Psychology \& Health, 20(1), 223-235. doi: 10.1080/08870440412331296053

Finlay, L. (2011). Phenomenology for therapists: Researching the lived world. Chichester: Wiley-Blackwell.

Giuntoli, G., Hughes, S., Karban, K., \& South, J. (2015). Towards a middle range theory of mental health and well-being effects of employment transitions: Findings from a qualitative study on unemployment during the 2009-2010 economic recession. Health, 19(4), 389-412. doi: 10.1177/1363459314554314

Glasscoe, C., \& Smith, J.A. (2011). Unravelling complexities involved in parenting a child with cystic fibrosis: An interpretative phenomenological analysis. Clinical Child Psychology and Psychiatry, 16(2), 279-298. doi: 10.1177/1359104510383207

Hammell, K. (2014). Belonging, occupation, and human well-being: An exploration. Canadian Journal of Occupational Therapy, 81(1), 39-50. doi: $10.1177 / 0008417413520489$

Handy, D., \& Davy, D. (2007). Gendered ageism: Older women's experience of employment agency practices. Asia Pacific Journal of Human Resources, 45(1), 85-99. doi: $10.1177 / 1038411107073606$

Harrison, J. (2001). 'It's none of my business': Gay and lesbian invisibility in aged care. Australian Occupational Therapy Journal, 48(3), 142-145. doi: 10.1046/j.00450766.2001.00262.x

Hart, A., Blincow, D. and Thomas, H. (2007). Resilient Therapy: Working with children and families. London: Routledge.

Hart, A., Gagnon, E., Eryigit-Madzwamuse, S., Cameron, J. Aranda, K., Rathbone, A. et al. (2016). Uniting resilience research and practice with an inequalities approach. SAGE Open, 6(4). doi:10.1177/2158244016682477

Johnson, A.M., \& Jackson, P.R. (2012). Golden parachutes: Changing the experience of unemployment for managers. Journal of Vocational Behaviour, 80(2), 474-485. doi: 10.1016/j.jvb.2011.08.001

Kielhofner, G. (2008). The basic concepts of human occupation. In G. Kielhofner, (Ed.), Model of Human Occupation (pp.11-23). Philadelphia: Lippincott Williams \& Wilkins.

Kossen, C., \& Hammer, S. (2010). Mature-aged job-seekers’ experience of Centrelink and the Job Network services in an Australian regional centre. Australian Journal of Career Development, 19(1), 45-53. doi: 10.1177/103841621001900109 
Laliberte-Rudman, D. (2002). Linking occupation and identity: Lessons learned through qualitative exploration. Journal of Occupational Science, 9(1), 12-19. doi: 10.1080/14427591.2002.9686489

Larkin, M., Watts, S., \& Clifton, E. (2006). Giving voice and making sense in interpretative phenomenological analysis. Qualitative Research in Psychology, 3(2), 102-120. doi: 10.1191/1478088706qp062oa

Larson, E., \& Zemke, R. (2003). Shaping the temporal patterns of our lives: The social coordination of occupation. Journal of Occupational Science, 10(2), 80-89. doi:10.1080/14427591.2003.9686514

Lincoln, Y.S., \& Guba, E.G. (1985). Naturalistic inquiry. London: SAGE Publications Ltd.

Lindsay, C. (2010). In a lonely place? Social networks, job seeking and the experience of long-term unemployment. Social Policy and Society, 9(1), 25-37. doi: 10.1017/S1474746409990170

Manning, A. (2009). You can't always get what you want: The impact of the UK JobSeeker's Allowance. Labour Economics, 16(3), 239-250. doi: 10.1016/j.labeco.2008.09.005

Meyrick, J. (2006). What is good qualitative research? A first step towards a comprehensive approach to judging rigour/quality. Journal of Health Psychology, 11(5), 799-808. doi: $10.1177 / 1359105306066643$

Nakai, Y., Chang, B., Snell, A.F., \& Fluckinger, C.D. (2011). Profiles of mature job-seekers: Connecting the needs and desires to work characteristics. Journal of Organizational Behaviour, 32, 155-172. doi: 10.1002/job.697

Office for National Statistics. (2015, January). Claimant count and vacancies dataset. Retrieved February 16, 2015 from http://www.ons.gov.uk/ons/rel/lms/labour-marketstatistics/january-2015/dataset--claimant-count-and-vacancies.html

Pemberton, S., \& Cox, D.L. (2015). Synchronisation: Co-ordinating time and occupation. Journal of Occupational Science, 22(3), 291-303. doi: 10.1080/14427591.2014.990496

Persson, D., Erlandsson, L., Eklund, M., \& Iwarsson, S. (2001). Value dimensions, meaning and complexity in human occupation- A tentative structure for analysis. Scandinavian Journal of Occupational Therapy, 8(1), 7-18. doi: 10.1080/11038120119727

Pringle, J., Drummond, J., McLafferty, E., \& Hendry, C. (2011). Interpretative phenomenological analysis: a discussion and critique. Nurse Researcher, 18(3), 2024. doi: 10.7748/nr2011.04.18.3.20.c8459 
Reed, K. D., Hocking, C. S., \& Smythe, L. A. (2011). Exploring the meaning of occupation: The case for phenomenology. Canadian Journal of Occupational Therapy, 78(5), 303-310. doi: 10.2182/cjot.2011.78.5.5

Russel, C. (2011). The use of narratives to contextualize the experiences and needs of unemployed, underemployed and displaced workers. Journal of Employment Counselling, 48(2), 50-62. doi: 10.1002/j.2161-1920.2011.tb00114.x

Smith, J.A., \& Flowers, P., \& Larkin, M. (2009). Interpretative phenomenological pnalysis: Theory, method and research. London: SAGE Publications Ltd.

Snelgrove, S. R. (2014). Conducting qualitative longitudinal research using interpretative phenomenological analysis, Nurse Researcher. 22(1), 20-25. doi:

10.7748/nr.22.1.20.e1277

Stavrova, O., Schlösser, T., \& Baumert, A. (2014). Life satisfaction and job-seeking behaviour of the unemployed: The effect of individual differences in justice sensitivity. Applied Psychology: An International Review, 63(4), 643-670. doi: 10.1111/apps.12009

Ungar, M., Brown, M., Liebenberg, L., Othman, R., Kwong, W. M., et al. (2007). Unique pathways to resilience across cultures. Adolescence, 42(166), 287-310. Retrieved from https://search.proquest.com/docview/195945008?accountid=9727

Unruh, A.M. (2004). Reflections on: 'So.. what do you do?' Occupation and the construction of identity. The Canadian Journal of Occupational Therapy, 71(5), 290-295. doi: 10.1177/000841740407100508

Vandermause, R.K., \& Fleming, S.E. (2011). Philosophical hermeneutic interviewing. International Journal of Qualitative Methods, 10(4), 367-377. doi: 10.1177/160940691101000405

Vesalainen, J., \& Vuori, J. (1999). Job-seeking, adaptation, and re-employment experiences of the unemployed: A 3-year follow-up. Journal of Community and Applied Social Psychology, 9(5), 383-394. doi: 10.1002/(SICI)1099-1298(199909/10)9:5<383::AIDCASP530>3.0.CO;2-0

Wanberg, C.R., Rotundo, M., \& Kanfer, R. (1999). Unemployed individuals: Motives, jobsearch competencies, and job-search constraints as predictors of job-seeking and reemployment. Journal of Applied Psychology, 84(6), 897-910. doi: 10.1037/00219010.84.6.897

Wanberg, C.R., Zhu, J., \& van Hooft, E.A. (2010). The job search grind: Perceived progress, self-reactions, and self-regulation of search effort. Academy of Management Journal, 53(4), 788-807. doi: 10.5465/AMJ.2010.52814599 
Whiteford, G. (2000). Occupational deprivation: Global challenge in the new millennium. British Journal of Occupational Therapy, 63(5), 200-204. doi:

10.1177/030802260006300503

Whitzman, C. (2006). At the intersection of invisibilities: Canadian women, homelessness and health outside the 'big city'. Gender, Place \& Culture: A Journal of Feminist Geography, 13(4), 383-399. doi: 10.1080/09663690600808502

Wilcock, A. (2006). An occupational perspective of health. (2nd ed.). Thorofare: SLACK Incorporated.

Wright, S. (2012). Welfare-to-work, agency and personal responsibility. Journal of Social Policy, 41(2), 309-328. doi: 10.1017/S0047279411001000 